This is the peer reviewed version of the following article: Egdell, V., and McQuaid, R. (2016) Supporting Disadvantaged Young People into Work: Insights from the Capability Approach. Social Policy \& Administration, 50: 1-18. doi: 10.1111/spol.12108., which has been published in final form at http://onlinelibrary.wiley.com/doi/10.1111/spol.12108/full. This article may be used for non-commercial purposes in accordance With Wiley Terms and Conditions for self-archiving. 


\title{
Supporting disadvantaged young people into work: insights from the Capability Approach
}

\begin{abstract}
The Capability Approach offers a perspective on the employment activation of young people that is concerned with their freedom to make choices that they value rather than focusing solely on outcomes, such as having to take any job. It incorporates empowerment and the individual and external conversion factors that influence the conversion of resources into functionings for young people, such as getting a job that they value. This paper considers the implications of using the Capability Approach as a lens for analysing youth activation polices. A more capability informed approach to employment activation would not measure success solely by the transition into work, but rather by whether it has improved the young person's capabilities, and might focus, for example, on more sustainable and valued careers and develop individuals' freedom of choice in the labour market. Using data from two UK case studies of third sector organizations that support young people into work, it explores these issues empirically, including the extent to which the programmes enhance the capabilities of beneficiaries. Conclusions on the implications of a Capability Approach for employment activation are made.
\end{abstract}

\section{Key words}

Youth unemployment; Capability Approach; Activation policy; Adaptive preference 


\section{Introduction}

The transition into work can be a complex process for young people, particularly for those from disadvantaged backgrounds (Brzinsky-Fay 2007). Many 'Work First' policies related to this transition are targeted primarily on entry into any employment. Yet there is increasing disenchantment with using solely employment or income as measures of welfare and wellbeing, and alternative measures have become increasingly important (Siglitz et al. 2009; Bleys 2012). This paper considers potential insights from the Capability Approach (CA) in providing an alternative perspective when considering local youth unemployment initiatives.

Principles of individual skills development with a focus on 'Work First approaches' and greater marketization of employment services have underpinned recent UK governments' approaches to employment activation. Work First approaches are concerned with rapid labour market entry, in with participants encouraged to take any job as quickly as possible, as this should improve their employability and wellbeing. However, success is often narrowly defined in terms of moving off benefits into work with limited consideration of employment sustainability and progression (Fuertes et al. 2014). Those out of work are often compelled to engage in activities, such as active job search, if they wish to receive state benefits or else suffer sanctions (Grover and Piggott 2013).

The European Union has responded to the high levels of youth unemployment with policies emphasizing both employment and social inclusion, such as the Youth Employment Initiative, Youth on the Move and the Youth Guarantee (European Commission 2011, 2013), although there is little discussion on the participation of young people in related decision making. There is also support for better matching of job entrant's skills and future labour 
market demand, through New Skills for New Jobs, and linking economic and social policy through an emphasis on more jobs and better jobs with both labour market flexibility and security, or 'flexicurity' (European Commission 2010). However, there is limited explicit consideration of the ability of young people to make the choices that they value.

The CA, initially developed by Sen $(1985,1998)$, focuses on the opportunities open to individuals and the real freedom they have to make choices that they value rather than just outcomes (such as entering any job); and has been used to examine labour market activation as well as the equalities and human rights position of individuals and groups (ChiapperoMartinetti 2008; Anand et al. 2009; Equality and Human Rights Commission 2009; Burchardt and Vizard 2011; Bussi and Dahmen 2012). The CA offers a useful perspective on activation policy. It seeks to reframe the debate on disadvantaged young jobseekers by highlighting their ability to choose what they value, their access to the resources that they need to get or improve their job and their motivation; rather than focusing primarily on a specific outcome (Bonvin and Orton 2009; Lindsay and McQuaid 2010).

Using data from two UK case studies of third sector organizations that support young people into work, this paper explores the extent to which these employment activation programmes, in their current form, can enhance the capabilities of beneficiaries and the implications of applying the a Capabilities Approach to employment activation.

\section{A Capability Approach to Employment Activation}

The CA is a theoretical framework related to people's wellbeing that focuses on the 'substantive' freedom of people to choose and be what they value as opposed to narrowly 
focusing on utility maximization or access to resources (Sen 1985, 1998; Robeyns 2006; Comim et al. 2008; Stiglitz et al. 2009). 'A person's advantage in terms of opportunities is judged to be lower than that of another if she has less capability - less real opportunity - to achieve those things that she has reason to value' (Sen 2009: 231). The approach is concerned with what people can do rather than what they actually do, together with the substantive freedom to choose a combination of functionings ('functionings' are 'beings' such as being safe or 'doings' such as voting) that they have reason to and actually value and the individual characteristics and the social environment that allow them to convert resources into such freedoms ('conversion factors') (Sen 2009). Capabilities are the combinations of functionings that they have freedom or real (not just formal or legal) opportunity to achieve (Sen 1992: 40). The CA recognizes differences and diversity between people, the different or multi-dimensional influences on someone's welfare and the crucial importance of autonomy and freedom of choice. Goerne (2010) highlights the distinction between commodities and capabilities, and capability and functionings made by the CA, which draws attention to human diversity, and so is a useful starting point for analysis.

Inequality is not only limited to material dimensions (e.g. income or wealth), but is affected by capabilities that represent the potential to achieve valued functionings, governed by factors such as having the opportunity to develop skills and the extent to which people are permitted to participate in work and learning (Walker and Unterhalter 2007). Capabilities include things that are only partly affected by a person's affluence (e.g. their ability to influence their job and working environment, the richness of family life, relationships, their capacity to influence the public sphere and politics and the sustainability of their lifestyles). The CA emphasizes empowerment and process freedom where individuals remain in control of their own choices (Vero et al. 2012). 
The CA is not a labour market theory; rather it can be considered as a framework to guide thought about how and what policies should seek to achieve (Lehwess-Litzmann 2012). It suggests that policies should consider capabilities in conjunction with other factors and does not specify any specific policies per se, but can influence the emphasis of the policy process. 'Evaluating capabilities rather than resources or outcomes shifts the axis of analysis to establishing and evaluating the conditions that enable individuals to take decisions based on what they have reason to value' (Walker and Unterhalter 2007: 3).From a labour market activation perspective, the CA suggests that the main objective of public action in the field of welfare should not be to put people back into work at all costs...but to enhance their real freedom of choice' (Bonvin 2009: 56). Hence CA informed policies should take a long-term perspective and promote an individuals' freedom to choose the work they have reason value.

The CA argues that there is no genuine empowerment if an individual is coerced into work (Bonvin and Moachon 2008). As such it might argue that employment activation programmes should allow individuals to refuse a job at a bearable cost (Orton 2011). However, this raises the question of both how the individuals (and society) values different jobs and who should undertake the 'less desirable' jobs. In contrast to the CA, other thinkers on welfare such as Mead (1992) have argued that those who are unemployed should not be entitled to such choice and be forced to engage in training or unpaid jobs in order to remain eligible for welfare benefits.

Empowerment can have contradictions between individual autonomy and control (Prujit and Yerkes 2014). For instance, integrating employment policies may empower people to search and get employment through a more tailored, 'client-centred' approach which better meets 
their actual needs rather than making them fit into rigid programmes, but also influences them to be adaptable to employment opportunities. The CA takes a wide perspective of empowerment and such 'supply-side' adaptability may sometimes reinforce paternalistic trends of directing the individual and not necessarily giving them real freedom to choose (Galster et al. 2009).

In terms of service design and implementation, the CA suggests that jobseekers and local stakeholders should have a voice in the development and content of programmes (Bonvin and Orton 2009). This assumption that people should be active participants in their own learning and personal development, and not just passive recipients of services, underlies in the CA. In order to do this, individuals need to have agency (Sen 1985) "rather than simply being shaped or instructed how to think' (Walker and Unterhalter 2007: 5). The CA suggests that jobseekers should be empowered through the provision of sufficient resources (e.g. welfare benefits) but they should also have access to appropriate conversion factors so that the resources available to them can be converted into enhanced capability to do work that they have reason to value. Conversion factors, such as appropriate labour market information, are likely to include both individual characteristics (e.g. skills and knowledge) and the socioeconomic context (e.g. a legal framework that combats discrimination and a labour market that offers valuable work opportunities). To empower an individual's capacity for independent action in learning and work (and so enhance their capabilities) they require appropriate information on a range of issues like skill levels needed to take opportunities for socio-economic mobility, the legal and policy context, and the accessibility and quality of job and learning opportunities. 
The CA acknowledges that individuals cannot always realize their capabilities because of structural inequalities and an individual's choices may be constrained by low expectations (Nussbaum 2000). The social environment needs to be shaped in order to make it more inclusive (Bonvin 2009). Such external conversion factors include the role of external, social and structural factors that affect the conversion of resources into capabilities or functionings, such as social stratification, labour market conditions or segregation, discrimination, the welfare system and activation and the possibilities or restrictions that are related to the (specific) programmes dealing with young people (Hollywood et al. 2012a). Therefore there also need to be demand side approaches in order to create opportunities for integration; and local agents need to be flexible so that they can meet the needs of specific local labour markets and jobseekers (Bonvin and Orton 2009), although this may be difficult to achieve in practice.

The CA can, with criticisms discussed below, offer a somewhat different perspective on activation to those adopted by the past UK governments (Lindsay et al. 2008) and help focus attention on sustainable job outcomes and the development of individuals' wellbeing through engaging them in employment that they have reason to value. The CA highlights the constraints, structures and processes which individuals operate under; and recognizes that individuals have diverse life goals. An implication of the CA is that the individual nature of a jobseeker's situation needs to be acknowledged (Lehwess-Litzmann 2012). So rather than just focusing on whether a young person is in work and their attributes and deficits; employment activation from a CA considers their access to resources to get or improve their job, motivation and what they value, and their ability to identify and take opportunities that they value (Bonvin and Orton 2009). 


\section{Methods}

\section{The Case Studies}

This research examines two third sector run programmes that provided training and work placements for disadvantaged young people. These programmes were not explicitly capability focused; rather the CA is being used as a lens to reflect on the programmes. Both programmes were selected as their focus was not solely on placing individuals into work (although this was a central aim) but also on addressing young people's wider personal, social and structural barriers. So through an implicit positive by-product, the programmes can be seen as enhancing capabilities.

Programme A provided supported work placements for disadvantaged 16-24 year olds. The programme comprised of a short two week induction period where participants were given training and guidance (depending on their needs as well as work placement requirements); followed by a six month work placement in a sector based on the participant's preferences. The availability of employers willing to participate could restrict choice, although the types of organizations that engaged with the programme were highly varied and in a variety of third sector organizations, the public sector, large multinationals and small local firms. Throughout the placement both the participants and the employer were supported by project workers. Generally in the first half participants continued to receive their unemployment benefits, and in the second half the employer met $50 \%$ of the wage cost with Programme A meeting the rest. Optional aftercare was offered to all participants leaving the programme. 
Programme B was a voluntary programme aimed at disadvantaged 16-25 year olds who were unemployed and not in education. It provided a mixture of, sometimes externally sourced, training and placements in specific work sectors. The structure of the programme depended on the sector, and the length varied from 5-10 weeks. As with Programme A, the types of employers that Programme B engaged with were varied within certain sectors. There appeared to be opportunities available in key organizations within these sectors. Participants on unemployment benefits could normally continue to receive these while on the programme, and their travel costs were also covered. Programmes were run throughout the year in different areas, with approximately 15 participants per programme. Demand was high and project workers spent several weeks selecting suitable participants. At the time of the data collection, Programme B was piloting further progression support.

\section{Data Collection}

In-depth, semi-structured interviews were conducted with managers, project workers and young people in both case study organizations. In Programme A interviews were conducted with 18 staff and 22 young people at different stages of the programme based at five different delivery sites. For Programme B a total of five staff were interviewed, as were five young people (all from the same course) both when they started and completed the programme.

Operationalising the $\mathrm{CA}$ raises a number of methodological questions (see ChiapperoMartinetti and Roche (2009), Hollywood et al. (2012b) and Lessman (2012) amongst others). The central difficulty is that Sen does not provide detail of how the CA might be applied empirically e.g. how to measure capabilities, freedom and opportunity for choice, rather than just directly observable functionings (Zimmerman 2006). Questions to project staff that 
sought to capture the young people's capabilities, freedom and opportunity for choice included:

- How do you identify the needs and aspirations of young people on the programme? How is the diversity of young people taken into account?

- What are the programme outcomes? Who decides what these outcomes should be? Do the service users/ex-service users have any say?

- How much choice/influence do young people have, for example, in setting the goals to be achieved?

The young people interviewed were asked questions such as:

- Do you feel like you had the freedom to choose the type of activities/work placement you did as part of the programme?

- What do you hope to do after finishing the programme? Are these the same plans that you had before starting on the programme?

The current authors acknowledge that the data gathered by no means gives a full insight into young people's capabilities, freedom and opportunity for choice. However, many of the questions asked and the data gathered do give some indicators of the absence/presence of capabilities (Hollywood et al. 2012b).

\section{Data Analysis}


Thematic content analysis was used to analyse the transcripts using a three-stage coding approach (Strauss and Corbin 1998). Following this coding a 'capabilities framework' was applied to allow further in-depth understanding into how the programmes could be viewed from a capabilities perspective. This framework focused upon the capabilities for voice, work and education. The capability for voice has been defined as 'the ability to express one's opinions and thoughts and to make them count in the course of public discussion' (Bonvin and Farvaque, 2006: 127). The capability for work is the real freedom to choose the job/activity one has reason to value and the capability for education is the real freedom to choose a training/curriculum programme that one has reason to value. As such the framework sought to address issues such as: whether the young people are enabled to choose work that they do and have reason to value, and if they are sufficiently empowered to have autonomy and voice in the delivery, implementation and evaluation of the programme.

\section{Empirical Findings}

The analysis of the findings is grouped around a framework of three inter-related central building blocks of a CA to employment activation: empowerment (young people's voice and choice in the delivery and implementation of the programmes); individual conversion factors (the skills and knowledge that affect beneficiaries' capacity to transform resources into capabilities); and external conversion factors (external social and structural factors that may affect the conversion of resources into capabilities, such as local labour market conditions) . These factors contribute to jobseekers' capabilities and functionings; and they highlight the importance of the resources an individual has, their motivation, what they value, and the external constraints. 


\section{Empowerment}

Employment activation from a CA should enhance jobseekers' real freedom of choice in the labour market (Bonvin 2009). Most of the young people from both programmes reported felt that they had the freedom to choose the types of activities that they engaged with while on the programmes. They felt that the project workers listened to them, something that had not always happened when they had engaged with other forms of employment support. "Interviewer: Have you had the freedom to choose what you want to do? Participant: Well they ask you the question straight up so you just answer that" (Female 17 years, Programme A)

There were various mechanisms for young people to exercise voice in programme development. For example, in Programme A young people were asked about what they wanted to do, rather than being put into any available job. Part of this process was also about developing the aspirations of the young people, as staff were also keen to broaden their horizons by questioning them about their motivations etc. It was felt that if the young people were in a job that did not interest them then they would be more likely to drop-out - although staff were only able to offer placements where there were employers willing to take the young people on. "Part of that is making sure that, it's easy to say well here is a job and get on with it, but if it's not the right job then they're not going to stick at it. So it is about making sure that it is a role that they're going to be happy in" (Project worker, Programme A).

Programme B also ensured that the young people were suitable for the course. However, as the programme was delivered in predefined sectors there was not necessarily the same extent of choice in terms of the placements on offer. However, through the programme young 
people's future options in the labour market were increased because they acquired work experience, making them more attractive to employers and enabling young people to make choices based on first-hand experience.

The CA also advocates that jobseekers and local stakeholders should have a voice in the development of programmes and that service providers are flexible to meet the needs of the young people they are supporting (Bonvin and Moachon 2008). While the core of Programme A remained the same there was flexibility in order to meet the needs of the local economy as well as the individuals. "In terms of the main means of delivery it's whatever is most appropriate. So what we don't do is be too prescriptive about the way in which it will work in a community...we keep the core of the programme the same, but we are happy to be flexible..." (Head office manager, Programme A).

The focus therefore was on the needs of the young people, and how they related to the local community. For example, some young people required very little support once they were in the workplace, while others needed continuous help and the support needed could "change week to week for some of them" (Project worker, Programme B). The targets and needs of funders had also to be met, therefore the extent to which young people have voice in programme design and delivery may be limited. In discussing how they coped with the potential tension between the young people's needs for support and encouragement and meeting the requirements of funders, staff argued that focusing on the young people's needs was a more effective way of meeting funder objectives. "We have to be aware of targets because if we don't meet the targets of the people that provide the funding, then we don't exist, but we've found the best way to meet those targets is not to focus on them, [but] to focus on what the young people want" (Project worker, Programme A). 


\section{Individual conversion factors}

The barriers faced by the young people on the programmes were often deeply engrained and many experienced multiple barriers to employment with most having few resources such as skills. For example these barriers include: individual factors (e.g. a lack of qualifications, skills and experience and a lack of aspirations, confidence and self-belief); personal circumstances (e.g. a lack of encouragement and careers advice from school, housing problems, literacy and numeracy support needs and being young parents); and external factors discussed below (McQuaid and Lindsay 2005). The programmes supported young people to deal with individual and personal barriers to employment. The 'individual conversion factors' influence the ability to convert the individual's resource characteristics into functionings, and they are central in enabling young people to live a life they have reason to value (Bonvin and Moachon 2008).

The young people often had only lower secondary level, or no, qualifications. It has been argued that little progress has been made towards social justice and equality in the education system (Reay et al. 2005). The process and structural attributes of family, and also community social capital, play an important role in young people's educational achievements (Israel et al. 2001). Young people who have grown up in poorer households have low levels of educational attainment and social class is a strong predictor of educational achievement and choices (Perry and Francis 2010). Goodman and Gregg (2010) have identified some of the reasons behind these trends, including: children from poorer families are less likely to have a rich learning environment; lower aspirations and expectations from parents and young people about entry to higher education; and the cognitive abilities of parents. 
The majority also had no significant work experience, and for those that did, it was fragmented and had not necessarily been fulfilling. "I did have one [job] but it was door to door commission based, that lasted 3 week and I quit. I got sick of going to people's doors when they are just in and cooking or eating. So I told them I just couldn't do it" (Male, 22 years, Programme A). Those young people with less education and in low status occupations are more vulnerable to fragmented transitions from education to employment than others (Bradley and Devadason 2008). As such, a transition to work may not imply that the capabilities of an individual have been developed, as young people may find themselves in insecure and precarious positions (Vero et al. 2012).

The young people often did not have clear aspirations and had not known what they wanted to do once they left school. "I couldn't really decide; it was quite hard so I just applied for anything” (Male, 21 years, Programme A). This has been exacerbated by the economic recession as young people may perceive that their aspirations will not necessarily be achievable (Reay 2005). One project worker in Programme A described having to explain what the word 'aspiration' means when asking what young people wanted to do.

Even when they had clear aspirations, these were often very narrow as the young people were not necessarily aware of the opportunities available to them or what they needed to do in order to achieve their aspirations (e.g. in terms of the experience needed, or other routes into their chosen profession). For example the occupations that the young people wanted to work in could be highly gendered (e.g. young women wanting to work in health and social care, and young men in construction). Job aspirations could also be shaped by the types of jobs held by those in the young people's family or other social networks. One young female 
outlined how she had considered finding a job in administration because she did not know what else to do, "I thought maybe I should try admin because there was nothing else I could really think of to do. I would want to do something else but I didn't think I could achieve it." (Female, 19 years, Programme A). The narrative of this participant also provides some evidence of 'adaptive preference' formation. This term has been used in the CA literature to describe how individuals living in situations of deprivation adjust their expectations downwards (Nussbaum 2000) and therefore do not have freedom to live the lives that they have reason to value.

Young people with uncertain occupational aspirations are less likely to be in employment or training (Yates et al. 2011). The young people also lacked confidence and self-belief and it was therefore important that the programmes helped to develop these and provide encouragement in order to keep them enthused about their participation in the programme. "Before I was just a nervous wreck when I came here like... I didn't have anything to do and then I thought I wasn't fit for it. Then I got stronger and bigger and things started to fall into place" (Male, 24 years, Programme A).

Staff from both programmes cited that it was important to identify the needs of the young people in order that the support they provided was appropriate and, in effect, helped improve their individual conversion factors. However, they did face difficulties doing this, and therefore it was important for the staff to build up rapport and trust with the young people. "It's tricky in the early stages but we invest a lot of time in building a relationship with them" (Project worker, Programme A). 
While the programmes tried to provide choices to the young people, there were constraints in delivering youth employability programmes in this way because of external conversion factors, including social conversion factors (social norms and practices) and local employment opportunities. Therefore the extent to which programmes could take a capabilities informed approach, and help convert the young people's resources into valued functionings, was limited by the lack of ability to shape the social environment and labour market conditions (Bonvin 2009).

The local labour markets meant that while young people might be asked in Programme A what they wanted to do, whether they would get a placement in this area depended on the job opportunities available. As such Programme A was still labour demand responsive, despite attempts to recruit employers with suitable attitudes and vacancies. "A lot is dependent on what employers we have and what vacancies we have...Partly it's listening to what they think they can do, what they want to do and partly it's what's actually out there, what's available" (Project worker, Programme A).

This was particularly relevant in sectors which had been badly hit by the recession. The programme beneficiaries were often in direct competition with more qualified jobseekers. "...the young people are almost being pushed down a bit so the graduates are taking slightly less skilled jobs I believe” (Project worker, Programme B). This pushing down the "job queue' exacerbated the marginalization of some young people, who may have found it difficult to find work even in more economically buoyant times. "[The program beneficiaries] are up against people that have come out of university, have degrees... They're going to get 
even more marginalized and it's like: what jobs are available for them?" (Project worker, Programme B).

Again there was some evidence of 'adaptive preference' formation. The young people were aware of the limited choices they might have in the labour market because of their lack of qualifications and experience for example. One young female commented that she needed to be 'realistic' in her aspirations, indicating a mechanism of negative self-selection away from a job that she would potentially find most rewarding. "The subjects I was really keen on were the arts and drama. I was best at these. But there are no opportunities to get jobs in these areas. I was not encouraged to get into jobs in the arts. I was more realistic" (Female, 17 years, Programme B).

There was careful selection of the employers that the programmes worked with. While recognizing that employers did have to meet business needs, the programmes sought to ensure that they could offer a nurturing and supportive environment for the young people. The programmes provided considerable support to the employers in terms of regular visits and contact, and helped them address problems the young people might be facing in the workplace. "You have got to keep the employers sweet to a certain extent as well because you don't want them turning round and saying it is not worth it, we are not working with you anymore. It is a very fine line” (Project worker, Programme A)

The project workers also had to be realistic with the employers about the potential barriers that the young people faced. They had to balance keeping employers involved, for example, using various strategies to mitigate the potential effects of an employer having a negative 
experience of a young person. So while the young people were at the centre of the programme, the characteristics and needs of employers were also carefully considered.

"It is really important that the employers understand what we do and what we're about, and also that they understand the client group that we're working with as well and I think we need to be realistic about what we can expect from the young people...if they have had a bad experience for example we try and make sure that the next time that they get someone who is really reliable just to try and keep them onside" (Project worker, Programme B)

The way in which the programmes themselves were structured, as a result of the demands by funders, also constrained the support that could be provided. Programme B only lasted between 5-10 weeks and therefore the amount of support for personal development was limited. However, six month progression support was offered to the young people, recognizing their longer term support needs and the programme worked in partnership with specialist providers. .

Although Programme A was longer the staff also cited a lack of time to address all of the needs of the young people. The programme was geared to providing a wide range of support but because some of the barriers experienced were deeply engrained, six months was often not enough to address them all. As one project worker commented: "some of the issues that we're dealing with here are quite deep seated" (Project worker, Programme A). 
Therefore, the programmes placed much emphasis on working with the 'right' young people. This was not 'creaming' of the most able young people so as to ensure the best results, but making sure that the young people they worked with were those who would benefit most from the programme and were sufficiently ready to enter employment given the limited time they could be supported so that they were not set up to fail.

"If I see somebody at the first interview and they can't make any eye contact, they don't know anything about themselves, they won't talk...I can't in two weeks make the difference that's going to give them a realistic chance of a job at the end of it. Sure we can take them through the programme and they'll pass it and they would go out on work placement and they would find something for them to do, but at the end of it they're not going to get it..." (Project worker, Programme B).

\section{Discussion and Conclusions}

This paper considered some insights from the CA into current approaches to youth employment activation in the UK. While the CA is not a labour market theory and Sen 'did not provide any form of checklist as to what the approach might mean in practice' (Orton 2011: 358) it does provide a useful framework for thought and analysis about the development of labour market policy. It also yields useful insights into possibilities for developing employment and income orientated welfare approaches, including Work First, into wider ranging approaches to welfare which focus more on capabilities and wellbeing. The CA is already being used by those who inform policy makers in some areas other than labour market policy (the CA forms part of the Equality Measurement Framework of the UK's Equality and Human Rights Commission (2009)). 
The CA can offer a valuable contribution to current approaches by asking us to increase the focus on the resources an individual has, their motivation and what they value, and how to convert these resources into functionings, when considering what is the best way to assist young people into valued work (Bonvin and Orton 2009). Recent UK policy appears to focus on the attributes and deficits of jobseekers, but the CA shows us that enhancing an individual's skills does not mean that they can necessarily lead a life that they have reason to value, and the transition to work is not always necessarily a positive move into 'quality' employment (Vero et al. 2012). As such capability friendly employment activation may promote 'access to options otherwise inaccessible to the unemployed workers, correcting inequalities in capabilities accumulated over the life course' (Bartelheimer et al. 2012: 43).

The two case study programmes illustrate some lessons about applying the CA to employment activation in practice, specifically focusing on three inter-related factors that are seen as contributing to job seeker's capabilities and functionings: empowerment (young people's voice and choice in the in the delivery and implementation of the programmes), individual conversion factors (the skills and knowledge that affect beneficiaries' capacity to transform resources into capabilities) and external conversion factors (external social and structural factors that may affect the conversion of resources into capabilities such as labour market conditions) .

Employment activation from a CA should empower beneficiaries to negotiate the content of a programme (Orton 2011). The approaches taken in the programmes demonstrate the importance of giving young people choice and developing their voice to choose (within the societal and labour market constraints) what they value when helping young people to 
prepare for, find and stay in work. The authors of this paper would argue that, where possible, focusing on work that individuals value could better help ensure the sustainability of job outcomes, develop their wellbeing and also perhaps help to reduce the likelihood that the individual cycles in and out of work. However, in terms of the fundamentals of the programmes, it is questionable as to the extent the young people in the two programmes were able to do influence these, and programme staff needed to ensure certain outcomes were achieved so as to meet the conditions of funding. As such, from a capabilities perspective, the young people have a limited influence over external conversion factors such as funding conditions. There is a need for future research into the application of the CA to employment activation to look at other mechanisms through which young people can have voice in programme development. While this research focused upon the choices offered to the individual and how they shaped their experiences, young people may also have voice in programme development at the level of the organisation through sitting on the board of trustees or forums within organisations, or engaging with government consultation for example.

A CA to employment activation is concerned with the collective framework rather than solely focusing on the individual (Zimmerman 2006) and the programmes highlight the importance of socially and culturally embedding young people's experiences of unemployment. The programmes take the view that if they do not recognize, and to some extent seek to address, the individual conversion factors faced by young people, then they will not be able to successfully find or stay in work. Disadvantaged youth may find that their personal circumstances and individual factors act as barriers to employment, and therefore employment activation needs to focus on issues beyond solely skills and qualification deficits. Their choices will operate under many constraints, such as the differing aspirations 
of young people and how they are formed, as well as the uncertainty of young people over their future career direction, often exacerbated by limited experience of the alternatives that might be available and that they might value. Hence high quality careers advice and an emphasis on future progression from the start of any employment are important.

The analysis of the programmes highlights difficulties that need to be overcome by any capability informed employment activation programme. While a 'narrow' view of employability focuses on supply-side issues, a 'broad' model of employability includes individual factors, personal circumstances, and external factors (McQuaid and Lindsay 2005). Empowering unemployed young people to choose the work that they have reason to value cannot be achieved without taking into account the importance of external conversion factors. One of the drawbacks of current welfare to work initiatives is that they are better suited to buoyant labour market conditions and it could be argued that capability friendly programmes could face the same limitations because of the lack of opportunities in the labour market. Even while taking a capability friendly approach, the programmes explored in this paper were still dependent upon the actual availability of suitable job and training opportunities. The extent to which demand from employers could be addressed so that young people could make 'true' rather than 'constrained' choices is questionable. Employer incentives offered by the current UK government (DWP 2012) may increase opportunities for young people, but the choices open to young people are still limited depending on the level and types of labour demand and which employers chose to take them up. While young people's choices may be developed it is still a choice shaped and constrained by the context of wider labour markets and education and training opportunities (including the prior educational opportunities they had at school). More generally structural inequalities continue to be important in shaping the trajectories of young people, despite the emphasis made on individual capacity. 
Thus the focus on what people have reason to value and their aspirations may raise problems. Some young people may have high expectations of choice in their life course and this may lead to tensions if suitable opportunities are not available (McDonald et al. 2011). It has been argued that it is not just a poverty of aspiration that is at the root of problems in the youth labour market, rather there is also a poverty of opportunity (Roberts and Atherton, 2011). Some young people, especially those less qualified, may feel forced to move quickly into the labour market (Schmelzer 2011). In terms of being able to gain employment that they value or realize their aspirations, this can be constrained by the jobs available and the skills of the young people themselves. In this context young people may need to know the paths required to meet their longer term ambitions as well as encouraging those who do not aim 'high enough' (Kintrea et al. 2011). The emphasis of European Union New Skills for New Jobs policy seeks to better develop and match young people's skills with future skills needs, although it does not sufficiently identify and include what young people value. Hence a CA lens could be used to adapt and refine such policies as well as bringing in wellbeing to the current narrow focus on any employment.

There have been a number of criticisms the CA that need to be considered. For example what makes up an appropriate set of capabilities, how are these capabilities measured or ranked and what are the alternatives that may be foregone if certain capabilities are promoted? What people value and different capabilities may change over time, as may functionings, and how these relate and interact are not clear. The choice of capabilities may also be subject to political interference and in some cases may be paternalistic. 
It would also be interesting for future research into the application of the CA to engage directly with, and seek to answer, questions raised by various thinkers on welfare. For example, as this paper has demonstrated, in applying a CA to employment activation, increasing the choice of jobseekers could result in some jobs being left unfilled because they are not seen by the young person to be rewarding or fulfilling. Questions can therefore be raised about who would undertake the jobs that jobseekers do not value. Would they be left unfilled or would they be taken by more disadvantaged people, perhaps reinforcing the exclusion of some young people? Indeed Dunn (2010: 17) argues that "academics and policy-makers have not addressed the question of "who should have to do the least attractive jobs?"', and would greater real choice prolong spells of unemployment and deepen disadvantage (Dunn 2013)? Further, how do we define the balance between the rights and obligations of people to fully participate in, and contribute positively to, society in terms of employment? How preferences of young people vary over time and may be influenced by factors including personality, personal circumstances and their environment, and how young people's value and knowledge of apparently unattractive entry-level jobs that may actually lead to potentially desirable career progression and fulfilment in the longer term, are all limited. These questions certainly warrant further analysis and discussion.

In summary, a CA can provide useful insights, albeit with limitations, into developing employment activation policies that both: take greater consideration of the job qualities and career prospects that are valued by participants rather than focus purely on entry to any job; and allow greater participation in the policy process by the unemployed participants, although not excluding other approaches to fostering empowerment. A more capability informed approach to employment activation would not measure success solely by the transition into work, but rather by whether it has improved the young person's capabilities, and might focus, 
for example, on more sustainable and valued careers and develop individuals' freedom of choice in the labour market. Jobseekers and local stakeholders would have a greater voice in programme development. Steps would also need to be taken to influence local labour markets so that they do not constrain the choices available to young people. While the authors of this paper recognize that some of these might be hard to achieve, a more CA focus could play a role in supporting job sustainability and greater empowerment among those most disadvantaged in the job market. In addition to that discussed above, further research is needed on the implications of a more capability informed approach to supporting young people into work; the links between capabilities and wellbeing; and using the CA as a lens to reflect on active labour market policies.

\section{Acknowledgements}

Removed for blind review.

\section{References}

Anand P., Hunter G., Carter I., Dowding K., van Hees M. (2009), the development of capability indicators, Journal of Human Development and Capabilities, 10: 125-52. Bartelheimer, P., Verd, J.M., Lehwess-Litzmann, R., López-Andreu, M. and Schmidt, T. (2012), Unemployment, intervention and capabilities. A comparative study of Germany and Spain, Transfer: European Review of Labour and Research, 18, 1: 31-44.

Bleys, B. (2012), Beyond GDP: classifying alternative measures for progress, Social Indicators Research, 109, 3: 355-376. 
Bonvin, J.M. (2009), Ensuring capability for work: outline of a capability-oriented labour market policy. In: K. Schneider and H.U. Otto (eds), From Employability Towards Capability, Luxembourg: Inter-Actions, pp. 55-69.

Bonvin, J.M. and Farvaque, N. (2006), "'Promoting capability for work: the role of local actors', in Deneulin, S., Nebel, M. and Sagovsky, N. (eds), Transforming Unjust Structures, Springer: Dordrecht, pp. 121-43.

Bonvin, J.M. and Moachon, E. (2008), Social integration policies for young marginalised: a capability approach, Social Work and Society, 6: 296-305.

Bonvin, J.M. and Orton, M. (2009), Activation policies and organisational innovation: the added value of the capability approach, International Journal of Sociology and Social Policy, 29, 11: 565-574.

Brzinsky-Fay, C. (2007), Lost in transition? Labour market entry sequences of school leavers in Europe, European Sociological Review, 23, 4: 409-422.

Burchardt, T. and Vizard, P. (2011), 'Operationalizing' the capability approach as a basis for equality and human rights monitoring in twenty-first-century Britain, Journal of Human Development and Capabilities, 12, 1: $91-119$.

Bussi, M. and Dahmen, S. (2012), When ideas circulate. A walk across disciplines and different uses of the 'capability approach', Transfer: European Review of Labour and Research, 18, 1: 91-95.

Chiappero-Martinetti, E. (2008), Time and income: empirical evidence on gender poverty and inequalities from a capability perspective. In: K. Basu K. and R. Kanbur (eds), Arguments For A Better World. Essays in Honour of Amartya Sen, Vol. 2, Society, Institutions and Development, Oxford: Oxford University Press, pp. 237-258. 
Chiappero-Martinetti, E. and Roche, J.M. (2009), Operationalization of the capability approach. In: E. Chiappero-Martinetti (ed), Debating global society: reach and limits of the capability approach. Fondazione Giangiacomo Feltrinelli, Milan.

Comim, F., M. Qizilbash and Alkire, S. (eds) (2008), The Capability Approach. Concepts, Measures and Applications, Cambridge: Cambridge University Press.

Dunn, A. (2013), Activation workers' perceptions of their longterm unemployed clients' attitudes towards employment, Journal of Social Policy, 42, 4: 799-817.

Dunn, A. (2010), The 'dole or drudgery' dilemma: education, the work ethic and unemployment, Social Policy and Administration, 44, 1: 1-19.

DWP (2012), Youth Contract. www.dwp.gov.uk/youth-contract/ (Accessed 27 August 2013).

Equality and Human Rights Commission (2009), Developing the Equality Measurement Framework: Selecting The Indicators by Alkire, S., Bastagli, F., Burchardt, T., Clark, D., Holder, H., Ibrahim, S., Munoz, M., Terrazas, P., Tsang T. and Vizard, P. London: Equality and Human Rights Commission.

European Commission (2010), Europe 2020, A Strategy For Smart, Sustainable And Inclusive Growth. Communication from the Commission, Brussels, 3.3.2010, COM (2010) 2020 final.

European Commission (2011), Youth Opportunities Initiative, Brussels, 20.12.2011, $\operatorname{COM}(2011) 933$ final.

European Commission (2013), Working Together For Europe's Young People, A Call To Action On Youth Unemployment, Brussels, COM(2013) 447 final.

Fenton, S. and Dermott, E. (2006), Fragmented careers?: Winners and losers in young adult labour markets, Work, Employment and Society, 20, 2: 205-221. 
Fuertes, V., Jantz, B., Klenk T. and McQuaid, R. (2014), Between cooperation and competition: the organisation of employment service delivery in the UK and Germany, International Journal of Social Welfare, (forthcoming).

Galster, D., Rosenstein, E. and Bonvin, J.M (2009), Assessing integrated employment policies against the capability approach: A Swiss case study, International Journal of Sociology and Social Policy, 29, 11/12: 637-648.

Goerne, A. (2010), The Capability Approach in Social Policy Analysis - Yet Another Concept? REC-WP Working Papers on the Reconciliation of Work and Welfare in Europe No. 03-2010. http://ssrn.com/abstract=1616210 or http://dx.doi.org/10.2139/ssrn.1616210 (Accessed 01 July 2014).

Goodman, A. and Gregg, P. (2010) Poorer children's educational attainment: how important are attitudes and behaviour? York: Joseph Rowntree Foundation.

Grover, C. and Piggott, L. (2013), A commentary on resistance to the UK's Work Experience programme: capitalism, exploitation and wage work, Critical Social Policy, 33, 3: 554-563. Hollywood, E., Egdell, V. and McQuaid, R. (2012a), Addressing the Issue of Disadvantaged Youth Seeking Work, Social Work and Society, 10, 1: 1-18.

Hollywood, E., Egdell, V., McQuaid, R. and Michel-Schertges, D. (2012b), Methodological issues in operationalising the capability approach in empirical research: an example of crosscountry research on youth unemployment in the EU, Social Work and Society, 10, 1: 120.Israel, G.D., Beaulieu, L.J. and Hartless, G. (2001), The influence of family and community social capital on educational achievement, Rural Sociology, 66, 1: 43-68. Kintrea, K., Bannister, J. and Pickering, J. (2010), Territoriality and disadvantage among young people: an exploratory study of six British neighbourhoods, Journal of Housing and the Built Environment, 25, 4: 447-465. 
Lehwess-Litzmann, R. (2012), What does flexicurity have to gain from the capabilityapproach?, Management Revue, 23, 2: 119-139.

Lessmann, O. (2012), Applying the capability approach empirically: an overview with special attention to labor. Management Revue, 23, 2, 98-118.

Lindsay, C., and McQuaid, R.W. (2010), The capability approach - a framework for labour market information on young adults. In: C.W. Larsen, J. Kipper and A. Schmid (eds), $\underline{\text { Regional Monitoring Approaches for the Reduction and the Prevention of Youth }}$ Unemployment in Europe. Muenchen: Rainer Hampp Verlag, pp. 152-159.

Lindsay, C., McQuaid, R.W. and M. Dutton (2008), Inter-agency co-operation and new approaches to employability, Social Policy and Administration, 42, 7: 715-732.

Mead, L. (1992), The new politics of poverty: the nonworking poor in America, New York: Harper Collins.

McDonald, P., Pini, B., Bailey, J. and Price, R. (2011), Young people's aspirations for education, work, family and leisure, Work, Employment and Society, 25, 1, 68-84.

McQuaid, R. and Lindsay, C. (2005) The concept of employability, Urban Studies, 42, 2, 197-219.

Nussbaum M.C. (2000), Women and Human Development: The Capabilities Approach. Cambridge: Cambridge University Press.

Orton, M. (2011), Flourishing lives: the capabilities approach as a framework for new thinking about employment, work and welfare in the 21st century, Work, Employment \& Society, 25, 2: 352-360.

Perry, E. and Francis, B. (2010), The social class gap for educational achievement. A review of the literature. London, RSA.

Prujit, H. and Yerkes, M.A. (2014), Empowerment as contested terrain, European Societies, $16,1: 48-67$. 
Reay, D. (2005), Beyond consciousness? The psychic landscape of social class, Sociology, 39, 5: 911-928.

Reay, D., David, M.E. and Ball, S. (2005), Degrees of choice. Social class, race and gender in higher education. Stoke, Trentham Books Limited.

Roberts, K. and Atherton, G., (2011), Career development among young people in Britain today: Poverty of aspiration or poverty of opportunity, International Journal of Education Administration and Policy Studies, 3, 5: 59-67.

Robeyns, I. (2006), The Capability Approach in Practice, Journal of Political Philosophy, 14: $351-376$.

Schmelzer, P. (2011), Unemployment in early career in the UK: a trap or a stepping stone?, Acta Sociologica, 54, 3: 251-265.

Sen, A.K. (1985), Commodities and Capabilities. Amsterdam: Elsevier.

Sen, A.K. (1998), Development as Freedom. New York: Knopf Press.

Sen, A. K. (1992), Inequality Reexamined. Cambridge, MA: Harvard University Press.

Sen, A. (2009), The Idea of Justice, London: Penguin.

Stiglitz, J., Sen, A. and Fitoussi, J-P. (2009), Report by the Commission on the Measurement of Economic Performance and Social Progress. Paris: Commission on the Measurement of Economic Performance and Social Progress.

Strauss, A. and Corbin, J. (1998), Basics of Qualitative Research. Techniques and Procedures for Developing Grounded Theory. Thousand Oaks: Sage Publications.

Vero, J., Bonvin, J-M., Lambert, M. and Moachon, E. (2012), Decoding the European dynamic employment security indicator through the lens of the capability approach. A comparison of the United Kingdom and Sweden, Transfer: European Review of Labour and Research, 18, 1: 55-67. 
Walker, M. and Unterhalter, E. (2007), The capability approach: Its potential for work in education. In: M. Walker and E. Unterhalter (eds), Amartya Sen's Capability Approach And $\underline{\text { Social Justice In Education, Basingstoke: Palgrave. }}$

Yates, S., Harris, A., Sabates, R., Staff, J. (2011), Early Occupational Aspirations and Fractured Transitions: A Study of Entry into "NEET" Status in the UK, Journal of Social Policy, 40, 3: 513-534.

Zimmermann, B. (2006), Pragmatism and the capability approach: challenges in social theory and empirical research, European Journal of Social Theory, 9, 4: 467-84. 